\title{
Recalling episodic and semantic information about famous faces and voices
}

\author{
LJubica Damjanovic and J. Richard Hanley \\ University of Essex, Colchester, England
}

\begin{abstract}
In this study, we used the distinction between remember and know $(\mathrm{R} / \mathrm{K})$ recognition responses to investigate the retrieval of episodic information during familiar face and voice recognition. The results showed that familiar faces presented in standard format were recognized with $\mathrm{R}$ responses on approximately $50 \%$ of the trials. The corresponding figure for voices was less than 20\%. Even when overall levels of recognition were matched between faces and voices by blurring the faces, significantly more R responses were observed for faces than for voices. Voices were significantly more likely to be recognized with K responses than were blurred faces. These findings indicate that episodic information was recalled more often from familiar faces than from familiar voices. The results also showed that episodic information about a familiar person was never recalled unless some semantic information, such as the person's occupation, was also retrieved.
\end{abstract}

In everyday life and in laboratory studies, the recognition of a face that we know is generally accompanied by the retrieval from semantic memory of further information about the person, such as his or her occupation or where he or she is typically encountered (Hanley \& Cowell, 1988; Hay, Young, \& Ellis, 1991; Young, Hay, \& Ellis, 1985). Much less is known about the availability in memory of episodes containing specific information about an occasion on which a familiar person was encountered. In this study, therefore, we investigated the retrieval of specific personal memories when famous faces are recognized and compared recall of episodic information from familiar faces with recall from familiar voices.

This is an issue that has been almost totally neglected in current theorizing about person recognition, in which it is generally assumed that person identification is carried out exclusively by the semantic memory system (Bruce \& Young, 1986; Burton, Bruce, \& Hancock, 1999; Valentine, Brennen, \& Bredart, 1996). However, recent research by Westmacott and Moscovitch (2003) and Westmacott, Black, Freedman, and Moscovitch (2003) showed that certain famous names were much more likely than others to be associated with retrieval of personal memories. Furthermore, these personally salient names were read and recognized more quickly than less salient names even when the two sets were equally familiar to the participants. These findings suggest that episodic memory might be more important in person recognition than has hitherto been suspected and indicates that it is important to investigate the extent to which personal memories might accompany recognition of familiar faces and voices.

In the experiment reported below, we, like Westmacott and Moscovitch (2003), investigated this issue by employing the remember/know $(\mathrm{R} / \mathrm{K})$ procedure originally used by Tulving (1985) and Gardiner (1988). In this procedure, participants are given a recognition test and asked to classify each item that they recognize into one of two categories, remember $(\mathrm{R})$ or know $(\mathrm{K})$. Typical instructions state that an $\mathrm{R}$ response means that recognition is accompanied by a specific recollection of the item's occurrence, such as an association or an image that the item evokes. A K response should be reported when the participant believes that he or she encountered the item previously but episodic information cannot be recalled. The $\mathrm{R} / \mathrm{K}$ procedure is a particularly useful tool in recognition memory because it allows the researcher to infer the presence of different contributions of remembering and knowing following experimental manipulations that have no effect on the overall number of items correctly recognized.

Since its inception, the $\mathrm{R} / \mathrm{K}$ paradigm has predominantly been used with verbal stimuli, such as words (e.g., Gardiner, Ramponi, \& Richardson-Klavehn, 1998) that are presented for study in an encoding phase and for recognition in a test phase. A small number of studies have applied the $\mathrm{R} / \mathrm{K}$ procedure to the recognition of novel faces (Brandt, Macrae, Schloerscheidt, \& Milne, 2003; Mäntylä, 1997), but it has never been applied to the recognition of familiar faces. This is surprising because $\mathrm{R} / \mathrm{K}$ instructions have consistently been defined to participants within a person recognition context. For example, Gardiner et al. (1998) gave the following example of remembering: "You recognize someone's face and perhaps remember talking to this person at a party the previous night" (p.23). Perfect, Williams, and Anderton-Brown (1995) defined knowing in terms of "recognizing someone in the street, but being

J. R. Hanley, rhanley@essex.ac.uk 
unable to place them, or remember anything about them other than that they are familiar" (p.173).

In the present study, we attempted to remedy this omission by investigating the contributions of $\mathrm{R} / \mathrm{K}$ judgments to the recognition of faces that were preexperimentally familiar to the participants. The experiment reported below was similar to those in Westmacott and Moscovitch (2003) and Westmacott, et al. (2003), but differed from most studies in which the $\mathrm{R} / \mathrm{K}$ paradigm has been used in that they did not involve a learning phase. Participants were shown a series of video clips of famous faces or voices and were asked to decide whether they recognized them and to indicate whether recognition was accompanied by a feeling of knowing or remembering. Like Westmacott et al. (2003), we asked the participants on every trial to justify their R/K decision by overtly recalling information about the person that had come to mind. Pilot work in our laboratory revealed that, otherwise, participants frequently make an $\mathrm{R}$ response whenever they can recall semantic information about a person (e.g., his or her occupation), regardless of whether a specific episodic memory has been accessed.

The first issue was whether the participants could meaningfully distinguish between recognition decisions for famous faces and voices that were accompanied by the specific recollection of an episode in which that face or voice was present ( $\mathrm{R}$ responses) and those that were not ( $\mathrm{K}$ responses). If so, it would be interesting to observe whether there were any differences between the number of $\mathrm{R}$ and $\mathrm{K}$ responses when recognition of famous faces was compared with recognition of famous voices. Hanley, Smith, and Hadfield (1998) showed that semantic information (e.g., an occupation or a name) was less likely to be recalled in response to a person's voice than in response to their face. Perhaps the same is true for retrieval of episodic information. However, when overall level of recognition was equated by blurring the faces, retrieval of semantic information was just as difficult for faces as for voices (Hanley \& Turner, 2000). In the experiment reported here, therefore, the participants were presented with voices, blurred faces, or standard faces of famous people and were asked to make $\mathrm{R}$ and $\mathrm{K}$ recognition decisions about them. If blurred faces were associated with more $\mathrm{R}$ and fewer $\mathrm{K}$ responses than were voices, despite being matched for overall recognition, this might suggest that representations of familiar voices in semantic memory are less strongly associated with representations in the episodic memory system than are the representations of faces that we know.

We also investigated the relationship between recall of semantic and episodic information. Is it possible to retrieve an episodic memory about a person's face or voice that we find familiar without recalling semantic information about him or her such as his or her occupation? If not, this would indicate that access to episodic information from a person's face or voice is strongly correlated with access to stored information about him or her in semantic memory. Is it possible to retrieve a personal memory about a face or voice that we find familiar without recalling the person's name? If not, this would suggest that access to the language system may be necessary before episodic information can be accessed from a face or voice.

\section{METHOD}

\section{Participants}

A total of 54 Essex University students took part in the experiment, many in partial fulfilment of course credit. Those who were not eligible for course credit were paid $£ 5$ for their participation. The sample consisted of 23 males and 31 females, with a mean age of 23.8 years. All the participants had normal or corrected-to-normal vision and normal hearing. All were native English speakers who had spent the past 15 years living in the U.K. Each participant was allocated to one of the three modality groups (standard faces, blurred faces, or voices). The standard face condition was run after the data from the blurred face and voice conditions had already been collected. The results from 3 participants in the blurred face condition were removed because they failed to obey the experimental instructions, leaving 15 participants in the blurred face group.

\section{Apparatus}

Presentation of the stimuli was by means of an Apple Mac G4 computer running QuickTime Player Media software. A 17-in. flat screen LCD color monitor was used to present the visual stimuli (standard faces and blurred faces). The QuickTime program was also used to present the voices through a pair of headphones. The computer keyboard was used by the experimenter to control the presentation rate of the stimuli.

\section{Design}

The experiment used a mixed factorial design with modality of presentation manipulated between subjects (standard faces or blurred faces). The within-subjects factor was subjective awareness ( $\mathrm{R}, \mathrm{K}$, or guess).

\section{Materials}

A series of extracts from television interviews with 48 famous people and 48 nonfamous people were used as the experimental materials. Each extract lasted for approximately $7 \mathrm{sec}$ and involved the person's saying something neutral that gave no clues as to his or her identity or occupation. The same extracts were used in the standard face, blurred face, and voice conditions. The famous items consisted of approximately equal numbers of people taken from the following media backgrounds: film, music, television, sport, comedy, and politics. The nonfamous people were selected from lifestyle documentary programs. The experimental trials were arranged in a random order into two blocks of 48 trials per block ( 24 famous and 24 nonfamous). Half the participants completed Block 1 and then Block 2, whereas the remaining half completed Block 2 and then Block 1, with a short break between blocks. A full list of the celebrities used in the experiment can be found in the Appendix.

In the voice condition, the audio tracks from both famous and nonfamous voices were formatted as an audio QuickTime file for presentation. It was clearly crucial that the famous voices could not be recognized on the basis of the speech content of what was being said. The guidelines outlined by Van Lancker, Kreiman, and Emmorey (1985), Van Lancker, Kreiman, and Wickens (1985), and Schweinberger, Herholz, and Steif (1997) in their selection of famous voices were followed. First, each speech sample was carefully selected to be free of any sort of speech trademarks (e.g., a catchphrase), background noises (studio audience), and identifying sounds (chat show theme tune). Second, each extract was spoken in an emotionally neutral tone and with normal intensity. Third, in a pilot study, each famous and nonfamous sample was presented in a written format to 10 participants. These participants were simply required to guess the famous person from the written samples. None of the celebrities used in the experiment were identified in this way. In addition, the participants were asked to indicate for each written statement whether they associated it with a famous or a nonfamous person. They were asked to write the letters $\mathrm{F}$ for famous and $\mathrm{N}$ for nonfamous, respectively. The results from this pilot study showed that the written texts from famous people were judged to have been 
spoken by a famous person slightly less frequently (45\%) than were those from nonfamous people $(53 \%)$. This difference was not significant $[t(9)=1.50]$.

In the standard and blurred face conditions, all the faces (famous and nonfamous) were edited through the multimedia software program Final Cut Pro to remove contextual background and clothing cues. The faces (with the audio track removed) were presented via the software program QuickTime Player.

In the blurred face condition, the same stimuli as those used in the standard face condition were reedited through the application of a Gaussian blur filter in Final Cut Pro. All the clips were rendered with a blur value of 26.25. A pilot study conducted in our laboratory showed that this level of blur was sufficient to reduce overall levels of recognition to a rate comparable to that for voices. To ensure that overall familiarity was matched in the voice and the blurred face conditions, 36 participants drawn from the same population as that in Experiment 1 were asked to rate the familiarity of the famous people on a scale of 0 (unfamiliar) to 3 (very familiar). Eighteen participants rated the blurred faces and gave them a mean familiarity rating of $1.33(S D=0.68)$. The remaining 18 participants gave the voices a mean familiarity rating of $1.35(S D=0.72)$. There was no significant difference between these means $[t(47)=0.18]$.

\section{Procedure}

The participants entered a quiet testing room and were seated approximately $70 \mathrm{~cm}$ from the computer monitor. The participants were informed that they would be presented with a sequence of standard faces/blurred faces/voices, depending on the group to which they were assigned. They were told that some of the faces/voices presented to them belonged to people who were well known in the British media, whereas the other faces/voices belonged to nonfamous individuals. In order to prevent any resolution of the blurred faces, the participants in this group were specifically instructed to refrain from moving in their seat. After the presentation of each item, the clip was paused for $20 \mathrm{sec}$ to enable the participants to make their response. For the initial recognition phase, the participants had to decide, for each item presented to them, whether they recognized it or not by saying "yes" or "no," respectively. If they answered "yes," they were instructed to provide an $\mathrm{R}, \mathrm{K}$ or guess response.

The $\mathrm{R}$ and $\mathrm{K}$ instructions in this experiment were available on a sheet of paper throughout the experiment. They were based on those employed by Westmacott and Moscovitch (2003) but were modified following a pilot study. Westmacott and Moscovitch told participants to make an $\mathrm{R}$ response if they could recall a particular episode in which the person was present and a $\mathrm{K}$ response "if they knew the identity of the famous person but could not remember a specific episode involving him or her" (p. 763). In our pilot study, we found that this definition of $\mathrm{K}$ did not capture knowing in the familiar-only sense that Gardiner et al. (1998) proposed. For example, a number of participants were sure that they recognized a face or voice as one that they had encountered before but could not assign their memory to the R category because they could not attribute an episodic/personal source to the face/voice. Neither could they use the K category, since this was contingent upon identifying who the person was in the absence of an episodic/personal memory. Following the pilot study, therefore, the $\mathrm{R} / \mathrm{K}$ definitions were modified to capture knowing in this familiar-only form. The $\mathrm{R}, \mathrm{K}$ and guess definitions incorporated the recognition of a famous person - in this case, Princess Diana. The three categories were defined as follows:

Remember: Please use this response if you can associate a specific episode or occasion in which you encountered the person. For example, "I remember watching a documentary about Al-Fayed and how he talked about Diana and Dodi's death." "I remember watching her funeral on TV and seeing all the flowers."

Know: Please use this response if you can associate some facts with the person, even though you cannot recall a specific episode or occasion in which you encountered them. For example,
"I know that's Diana and her sons are called William and Harry, but I can't recall a specific occasion in which I heard (saw) her voice (face)." You can also use this category if you find the face/voice highly familiar and you are confident that you recognize them but cannot recall any facts about the person. For example, "I know that I have heard (seen) this voice (face) before, but I don't know who it belongs to."

Guess: Please use this category if you are not sure whether you have heard (saw) the voice (face) before. If you would like to guess that you may have encountered this face/voice previously, please use this category.

These definitions were visually presented to the participants and were available throughout the duration of the testing phase. As soon as the participants made an $\mathrm{R}, \mathrm{K}$, or guess response, they were asked to describe the first thing that came to mind and were prompted to point to the definitions and state how their $\mathrm{R}, \mathrm{K}$, or guess response fitted in with the definitions provided by the experimenter. By questioning the participants at the time that they made an $\mathrm{R}$ response, we were able to ensure that they were able to report a specific episode. This procedure also allowed us to estimate how often the participants were able to recall the occupation and name of a person when they made an $\mathrm{R}$ response. This procedure allowed the experimenter to directly assess whether the participants were using the response categories in a valid way. All 3 participants who were excluded from the experiment used the guess category incorrectly by recalling detailed information about most of the people that they claimed to be recognizing on the basis of a guess.

\section{RESULTS}

\section{Overall Recognition}

The overall means for recognition are displayed in Table 1 . There was a significant effect of modality group on the number of hits $\left[F(2,48)=32.72, M S_{\mathrm{e}}=0.014\right]$ and also on the number of false alarms $[F(2,48)=5.63$, $\left.M S_{\mathrm{e}}=0.008\right]$. A significance level of .05 was set for all the analyses reported in this article. Post hoc analyses (Newman-Keuls tests) revealed that there were significantly more hits in the standard face condition than in the blurred face and voice conditions and significantly fewer false alarms in the standard face condition than in the blurred face and voice conditions. The voice and the blurred face conditions did not differ significantly in terms of either hits or false alarms.

$A^{\prime}$ was used as a measure of sensitivity, and $B^{\prime \prime} D$ was used as a measure of bias (see Donaldson, 1996). There was a significant effect of modality group on sensitivity $\left[F(2,48)=40.99, M S_{\mathrm{e}}=0.003\right]$. Post hoc analyses revealed significantly greater sensitivity in the standard face condition than in the blurred face and voice conditions,

Table 1

Mean Overall Proportions of Hits and False Alarms Plus $\boldsymbol{A}^{\prime}$ (Sensitivity) and $B^{\prime \prime} D$ (Bias) Measures for the Standard Face, Blurred Face, and Voice Conditions (With Standard Deviations)

\begin{tabular}{|c|c|c|c|c|c|c|c|c|}
\hline \multirow[b]{2}{*}{ Condition } & \multicolumn{2}{|c|}{ Hits } & \multicolumn{2}{|c|}{$\begin{array}{l}\text { False } \\
\text { Alarms }\end{array}$} & \multicolumn{2}{|c|}{$A^{\prime}$} & \multicolumn{2}{|c|}{$B^{\prime \prime} D$} \\
\hline & $M$ & $S D$ & $M$ & $S D$ & $M$ & $S D$ & $M$ & $S D$ \\
\hline Standard faces & .89 & .08 & .08 & .07 & .95 & .03 & .23 & .71 \\
\hline Blurred faces & .59 & .17 & .18 & .10 & .80 & .05 & .41 & .47 \\
\hline Voices & 61 & .11 & .14 & .10 & .83 & .07 & .56 & .35 \\
\hline
\end{tabular}

Note $-A^{\prime}$ values range from 0 (no discrimination) to 1.0 (perfect discrimination), with chance performance represented by an $A^{\prime}$ value of .50 . 
but no significant difference between the voice and the blurred face conditions. There was no significant effect of modality on bias $\left[F(2,48)=1.65, M S_{\mathrm{e}}=0.287\right]$.

\section{Remember and Know Responses}

The number of recognition hits associated with $\mathrm{R}, \mathrm{K}$, and guess responses is shown in Table 2. A $3 \times 3$ (modality $\times$ state of awareness) ANOVA revealed a main effect of modality $\left[F(2,48)=33.10, M S_{\mathrm{e}}=0.005\right]$ and a main effect of subjective awareness $\left[F(2,48)=48.16, M S_{\mathrm{e}}=\right.$ $0.005]$. The modality $\times$ subjective awareness interaction was also significant $\left[F(4,96)=15.80, M S_{\mathrm{e}}=0.013\right]$.

Post hoc analyses showed that there were significantly more $\mathrm{R}$ responses in the standard face condition than in the blurred face or voice condition and significantly more $\mathrm{R}$ responses in the blurred face condition than in the voice condition. There were significantly more $\mathrm{K}$ responses in the voice and standard face conditions than in the blurred face condition. There were significantly more guess responses in the blurred face condition than in the standard face and voice conditions.

In both the standard and the blurred face conditions, there were significantly more $\mathrm{R}$ responses than $\mathrm{K}$ responses. In the voice condition, however, there were significantly more $\mathrm{K}$ than $\mathrm{R}$ responses. In the voice and standard face conditions, the number of guess responses was significantly lower than the number of $\mathrm{R}$ and $\mathrm{K}$ responses. In the blurred face condition, there were significantly fewer guess than $\mathrm{R}$ responses but no significant difference in the number of guess and $\mathrm{K}$ responses.

The proportions of false alarms associated with $\mathrm{R}, \mathrm{K}$, and guess responses are shown in Table 3 . A $3 \times 3$ (modality $\times$ state of awareness) ANOVA revealed a main effect of modality $\left[F(2,48)=6.34, M S_{\mathrm{e}}=0.003\right]$ and a main effect of subjective awareness $\left[F(2,48)=23.14, M S_{\mathrm{e}}=\right.$ $0.003]$. The modality $\times$ subjective awareness interaction was also significant $\left[F(4,96)=4.75, M S_{\mathrm{e}}=0.003\right]$. Post hoc analyses showed that there was an equal number of $\mathrm{R}$ false alarms in the three conditions. There were signifi-

Table 2

Mean Proportions of Correct Remember, Know, and Guess Responses for the Standard Face, Blurred Face, and Voice Conditions (With Standard Deviations)

\begin{tabular}{|c|c|c|c|c|c|c|}
\hline \multirow[b]{2}{*}{ Condition } & \multicolumn{2}{|c|}{ Remember } & \multicolumn{2}{|c|}{ Know } & \multicolumn{2}{|c|}{ Guess } \\
\hline & $M$ & $S D$ & $M$ & $S D$ & $M$ & $S D$ \\
\hline Standard faces & .49 & .12 & .32 & .15 & .08 & .02 \\
\hline Blurred faces & .27 & .13 & .17 & .09 & .15 & .08 \\
\hline Voices & .19 & .08 & .33 & .11 & .09 & .07 \\
\hline
\end{tabular}

Table 3

Mean Proportions of False Alarms for Remember, Know, and Guess Responses in the Standard Face, Blurred Face, and Voice Conditions (With Standard Deviations)

\begin{tabular}{lcclccccc}
\hline & \multicolumn{2}{c}{ Remember } & & \multicolumn{2}{c}{ Know } & & \multicolumn{2}{c}{ Guess } \\
\cline { 2 - 3 } \cline { 8 - 9 } \multicolumn{1}{c}{ Condition } & $M$ & $S D$ & & $M$ & $S D$ & & $M$ & $S D$ \\
\hline Standard faces & 0 & 0 & & 0 & 0 & & .07 & .06 \\
Blurred faces & .02 & .03 & & .05 & .05 & & .12 & .09 \\
Voices & .01 & 0 & & .08 & .07 & & .06 & .08 \\
\hline
\end{tabular}

cantly more $\mathrm{K}$ false alarms in the blurred face and voice conditions than in the standard face condition. There were significantly more guess false alarms in the blurred face condition than in the voice or standard face conditions. In the standard and blurred face conditions, there were significantly more false alarms associated with guess responses than with $\mathrm{R}$ or $\mathrm{K}$ responses ( $\mathrm{R}$ and $\mathrm{K}$ did not differ significantly). In the voice condition, there were significantly fewest false alarms with $\mathrm{R}$ responses (guess and $\mathrm{K}$ did not differ significantly).

\section{Descriptions of Remembering, Knowing, and Guessing}

All of the $\mathrm{R}$ responses were associated with retrieval of a specific episodic memory-for example, "Rod Stewart. Listening to songs in Mum's car when I was younger. . . Maggie May. . . Mum used to sing along to that song" ( $\mathrm{R}$ response for Rod Stewart, who is a singer). $\mathrm{K}$ responses comprised either a familiarity-only experience or retrieval of semantic information, but no specific event. Typical examples were, respectively as follows: "I recognize the voice, don't know name or what they do" (K response for Jarvis Cocker, who is a singer); "I know it's Bruce Forsyth, but I don't have a specific memory for him. I know he hosted 'The Generation Game' for years" (K response for Bruce Forsyth, who is an entertainer). An example of a guess response was "Guess I've heard it before. It sounds like a musician" (guess response for Sting, who is a singer).

In the standard face condition, $82 \%$ of the $\mathrm{K}$ responses were associated with recall of semantic information about the famous person; the corresponding figures were $63 \%$ in the blurred face condition and $40 \%$ in the voice condition. The difference between these means was significant $\left[F(2,48)=11.80, M S_{\mathrm{e}}=0.062\right]$. Post hoc analyses showed that when a $\mathrm{K}$ response was reported, semantic information was significantly most likely to be recalled in the standard face condition and significantly least likely to be recalled in the voice condition.

We also investigated the amount of semantic information that the participants were able to recall when they made an $\mathrm{R}$ response. This revealed that on every occasion in the voice, standard face, and blurred face conditions that they made an $\mathrm{R}$ response, the participants recalled information about the person's occupation. Eighty-nine percent of the $\mathrm{R}$ responses in the blurred face condition, $94 \%$ of the $\mathrm{R}$ responses in the standard face condition, and $97 \%$ of the $\mathrm{R}$ responses in the voice condition were also associated with recall of a name (not necessarily the correct name). Therefore, although the participants were generally able to recall a name when they made an R response, this was not always the case; it does not appear that recall of episodic information requires prior recall of the person's name.

There were strong significant correlations between the mean number of $\mathrm{R}$ responses that a famous person received and his or her mean preexperimental familiarity rating (see the Method section). The correlations were .68 in the standard face condition, .83 in the blurred face condition, and .70 in the voice condition. This shows that, 
overwhelmingly, episodic memories were most likely to be recalled about those famous people who were most familiar to the participants. These correlations were stronger than those reported between familiarity and recall of episodic information for names by Westmacott and Moscovitch (2003), which were 296 for 65- to 80-year-olds and .378 for 45 - to 55 -year-olds. Of course, our sample size was smaller (48 vs. 236 celebrities), and we made no attempt to include people that might be high in emotionality, relative to their familiarity (e.g., Lee Harvey Oswald and Harold Shipman). From our results, however, it would not be possible to produce sets of people who were matched for familiarity but differed in terms of the probability that they would elicit an $\mathrm{R}$ response. In this experiment, the famous people who elicited the most $\mathrm{R}$ responses were the celebrities that the participants found the most familiar.

\section{DISCUSSION}

The main purpose of this study was to investigate the recall of episodic information from familiar faces and voices. The results showed that the participants made $\mathrm{R}$ responses on approximately half of the trials (.49) in which famous faces were presented in standard format. When the number of $\mathrm{R}$ responses is conditionalized on the hit rate for standard faces (.89), the probability of episodic information being recalled for a famous face that was found familiar is .55. This finding demonstrates that the participants were able to provide episodic information about a relatively high proportion of familiar faces when explicitly encouraged to do so. Nevertheless, the participants were not as successful at recalling episodic information about familiar people as they were at recalling semantic information. One possible explanation is that whereas semantic information about a familiar person remains fairly stable over time, each episode in which a familiar person is encountered is different. As a consequence, it may be relatively difficult to bring any one of them to mind.

The proportion of $\mathrm{R}$ responses observed with standard faces was somewhat higher than the number of $\mathrm{R}$ responses given to famous names by Westmacott et al.'s (2003) normal participants (45-80 years old) who made $\mathrm{R}$ responses on approximately $36 \%$ of the trials. It is possible that performance was higher for standard faces in the present study than it was for names in Westmacott et al.'s study because of potential differences in the familiarity of the celebrities who were used in the two studies. It would certainly be interesting to see whether names would produce as many $\mathrm{R}$ responses as standard faces if the stimuli used in the present experiment were presented as names.

In the voice condition, the proportion of $\mathrm{R}$ responses was only .19. When conditionalized on the hit rate for voices (.61), the probability that a famous voice that had been found familiar would elicit episodic information was only .31. Even when the hit rate for faces was reduced to the same level as that for voices by blurring the faces, the participants in the blurred face condition made significantly more $\mathrm{R}$ responses than did the participants in the voice condition. Correspondingly, there were significantly more $\mathrm{K}$ responses to voices than to blurred faces. Whereas blurred faces were more likely to be recognized on the basis of $\mathrm{R}$ responses than on the basis of $\mathrm{K}$ responses, voices were more likely to be recognized on the basis of $\mathrm{K}$ responses than on the basis of $\mathrm{R}$ responses. These findings show very clearly that episodic information is more likely to be recalled from faces that are found familiar than from voices that are found familiar.

One possible explanation for why there were fewer $\mathrm{R}$ responses for voices than for faces is that the episodic memory system has stronger connections to the face recognition system than to the voice recognition system. Alternatively, the availability of episodic information may be directly related to the availability of semantic information. Because there were more $\mathrm{R}$ and $\mathrm{K}$ responses that were associated with recall of the person's occupation in the blurred face condition than in the voice condition, superior retrieval of episodic information from faces than from voices may be a consequence of superior retrieval of semantic information from faces than from voices

The finding that more semantic information was recalled from blurred faces than from voices differs from what was observed by Hanley and Turner (2000), who found that occupations were recalled equally well from faces and from voices when recognition performance was matched by blurring the faces. There are a number of methodological improvements in the present study, as compared with the procedure used by Hanley and Turner, that might explain this discrepancy. Most important, much stricter criteria were used in the present experiment in order to ensure that a voice could not be recognized on the basis of the context or the content of what was being said than was the case in Hanley and Turner's experiment. If they were present in the voice extracts used by Hanley and Turner, these contextual cues could have led to an artificially high level of correct occupations being recalled in the voice condition when the person had not been genuinely identified.

These results potentially raise problems for a model of person recognition such as that put forward by Burton et al. (1999), in which familiarity decisions are made at a point in the system when the face and voice recognition systems have already converged on the modality-free person identity node (PIN). According to this model, if it is difficult to recall semantic or episodic information about a face that is found familiar, it should also be difficult to recall such information from that person's voice when it is found familiar. One way in which Burton et al.'s model could explain these findings would be if the voices were being recognized on the basis of lower levels of activation of the PIN than is the case for faces (see Hanley \& Turner, 2000 , for a simulation of such a situation). Although this possibility cannot be ruled out for certain, it does seem unlikely, given that overall, recognition was matched in the voice and the blurred face conditions and that the voices and blurred faces were matched for familiarity preexperimentally. Contrary to Burton et al., therefore, the results are consistent with the possibility that there are closer connections between the face recognition system and information stored in semantic memory (such as the person's occupation) than between the voice recognition 
system and information stored in semantic memory. It is, however, possible that the attempt to retrieve episodic memories from voices was particularly effortful and may have interfered in some way with the recall of semantic information. The different results obtained by Hanley and Turner may, therefore, have occurred because their study did not require the retrieval of episodic information.

In conclusion, our explanation of the findings has emphasized the importance of the retrieval of semantic information about a person if episodic information is also to be recalled. Because episodic information about a person was never retrieved unless their occupation was also recalled, our tentative interpretation is that episodic memory is accessed after information has been recalled from semantic memory. An alternative possibility is that, as Westmacott et al. (2003) claim, "in a typical retrieval event the autobiographically significant and generic aspects of a concept's meaning are activated simultaneously" (p.46). From this perspective, it might be argued that episodic information is sometimes recalled prior to semantic information but that a person's occupation can be inferred from the contents of any episodic memory that is retrieved about them. In the absence of any latency data, we acknowledge that it would be unwise to draw strong conclusions about the order in which different types of information are recalled from memory. We hope that further empirical investigations will be conducted in the future to investigate these issues in more detail.

\section{AUTHOR NOTE}

Correspondence concerning this article should be sent to J. R. Hanley, Department of Psychology, University of Essex, Colchester, Essex C04 3SQ, England (e-mail: rhanley@essex.ac.uk).

\section{REFERENCES}

Brandt, K., Macrae, N. C., Schloerscheidt, A. M., \& Milne, A. B. (2003). Remembering or knowing others? Person recognition and recollective experience. Memory, 11, 89-100.

Bruce, V., \& Young, A. W. (1986). Understanding face recognition. British Journal of Psychology, 77, 305-327.

Burton, A. M., Bruce, V., \& Hancock, P. J. B. (1999). From pixels to people: A model of familiar face recognition. Cognitive Science, 23, 1-31.
Donaldson, W. (1996). The role of decision processes in remembering and knowing. Memory \& Cognition, 24, 523-533.

GARDINER, J. M. (1988). Functional aspects of recollective experience. Memory \& Cognition, 16, 309-313.

Gardiner, J. M., Ramponi, C., \& Richardson-Klavehn, A. (1998). Experiences of remembering, knowing, and guessing. Consciousness \& Cognition, 7, 1-26.

Hanley, J. R., \& Cowell, E. S. (1988). The effects of different types of retrieval cues on the recall of names of famous faces. Memory \& Cognition, 16, 545-555.

Hanley, J. R., Smith, S. T., \& Hadfield, J. (1998). I recognize you but I can't place you: An investigation of familiar-only experiences during tests of voice and face recognition. Quarterly Journal of Experimental Psychology, 51A, 179-195.

HANLEY, J. R., \& TuRner, J. M. (2000). Why are familiar-only experiences more frequent for voices than for faces? Quarterly Journal of Experimental Psychology, 53A, 1105-1116.

Hay, D. C., Young, A. W., \& Ellis, A. W. (1991). Routes through the face recognition system. Quarterly Journal of Experimental Psychology, 43A, 761-791.

MäNTYLÄ, T. (1997). Recollection of faces: Remembering differences and knowing similarities. Journal of Experimental Psychology: Learning, Memory, \& Cognition, 23, 1203-1216.

Perfect, T. J., Williams, R. B., \& Anderton-Brown, C. (1995). Age differences in reported recollective experience are due to encoding effects, not response bias. Memory, 3, 169-186.

Schweinberger, S. R., Herholz, A., \& Steif, V. (1997). Auditory long-term memory: Repetition priming of voice recognition. Quarterly Journal of Experimental Psychology, 50A, 498-517.

Tulving, E. (1985). Memory and consciousness. Canadian Psychology, 26, 1-12.

Valentine, T., Brennen, T., \& Bredart, S. (1996). The cognitive psychology of proper names. London: Routledge.

Van LancKer, D., Kreiman, J., \& Emmorey, K. (1985). Familiar voice recognition: Patterns and parameters. I: Recognition of backward voices. Journal of Phonetics, 13, 19-38.

Van Lancker, D., Kreiman, J., \& Wickens, T. D. (1985). Familiar voice recognition: Patterns and parameters. II: Recognition of ratealtered voices. Journal of Phonetics, 13, 39-52.

Westmacott, R., Black, S. E., Freedman, M., \& Moscovitch, M. (2003). The contribution of autobiographical significance to semantic memory: Evidence from Alzheimer's disease, semantic dementia, and amnesia. Neuropsychologia, 42, 25-48.

Westmacott, R., \& Moscovitch, M. (2003). The contribution of autobiographical significance to semantic memory. Memory \& Cognition, 31, 761-774.

Young, A. W., Hay, D. C., \& Ellis, A. W. (1985). The faces that launched a thousand slips: Everyday difficulties and errors in recognizing people. Quarterly Journal of Experimental Psychology, 38A, 297-318.

APPENDIX

List of Celebrities Used in the Study

\begin{tabular}{llll}
\hline Anne Kirk Bride & Eamon Holmes & Kirsty Young & Ronan Keating \\
Anne Robinson & Elton John & Liam Neeson & Ronnie Barker \\
Anne Widdecombe & Emma Bunton & Linford Christie & Ronnie Wood \\
Anthea Turner & Esther Rantzen & Lulu & Sally Gunnell \\
Bob Monkhouse & Gary Lineker & Margaret Thatcher & Sean Connery \\
Boy George & George Best & Mark Lamarr & Sophie Ellis Bextor \\
Bruce Forsyth & Jarvis Cocker & Michael Barrymore & Stephen Fry \\
Carol Voderman & Joanna Lumley & Michael Heseltine & Sting \\
Chris Eubank & John Major & Michael Portillo & Terry Wogan \\
Chris Tarrant & Johnny Vegas & Noddy Holder & Tom Jones \\
David Beckham & Julie Walters & Ricky Tomlinson & Ulrika Johnsson \\
Dawn French & Kate Winslet & Rod Stewart & Vinnie Jones \\
\hline
\end{tabular}

(Manuscript received October 6, 2005;

revision accepted for publication June 11, 2006.) 